\title{
El Estado y la informalidad urbana. Perú en el siglo XXI
}

\author{
Julio Calderón Cockburn \\ Universidad Nacional Mayor de San Marcos \\ cockburnjulio@gmail.com
}

\begin{abstract}
RESUMEN
Este artículo busca entender cómo la acción de gobierno puede generar la informalidad urbana y sus consecuencias. Tomando como referencia el caso peruano, este artículo no busca abundar en información empírica, ${ }^{1}$ sino reflexionar acerca de la relación conceptual entre Estado e informalidad. Al respecto, conviene distinguir la informalidad laboral (definida por las condiciones de trabajo en relación a un marco jurídico vigente) de la informalidad urbana, referida al modo en que grupos sociales acceden al suelo, se proveen y gestionan servicios básicos y construyen su vivienda. En el Perú, entre 1990-2019, se ha desplegado un modelo de libre mercado que ha buscado promover la inversión privada y la empresa formal y, explícitamente, se ha planteado reducir la informalidad. Se considerarán cuatro aspectos: la política de vivienda y la política de titulación de la propiedad, ambos destinados a frenar la informalidad, la entrega de constancias o certificados de posesión municipal y, finalmente, el paso del predominio de invasiones al de mercados ilegales de tierras en el acceso al suelo. El artículo se ha basado en la revisión de información secundaria, especialmente aquella producida por organismos del Estado peruano. De modo excepcional se han considerado investigaciones empíricas de académicos peruanos y tesis universitarias.
\end{abstract}

Palabras clave: Informalidad urbana, política pública, vivienda, titulación, suelo.

\section{The state $\&$ urban informality. Peru in the 21 st century}

\begin{abstract}
The objective of this article is to understand how the action of a Government can generate Urban Informality and what its consequences are. Taking Peru as a reference, this article does not seek to share an idea or opinion with empirical information,[1] but rather to reflect on the cause- effect connections between the State and Informality. In this sense, it is convenient to distinguish Labour Informality (defined by the labour conditions, in relation to the current Legal Framework) from Urban Informality (how social groups access land, provide basic services and build their homes). In Peru, between 1990 and 2019, a free market model has been developing and it has sought to promote private investment and formal businesses and, mainly, it has considered reducing informality. There are four aspects that we consider: the Housing Policy, the Property Titling Policy (aimed at curbing informality), the delivery of Certificates by the City Council and, finally, the passage of the large number of invasions to illegal land markets to access a piece of land. This article has been based on the revieaw of secondary information source, especially the one produced by Peruvian State Agencies. Exceptionally, we have considered empirical researches of some Peruvian professors along with several Academic Theses.
\end{abstract}

KeYwords: Urban Informality, Public policy, housing, land titling, land.

1 Este artículo constituye uno de los capítulos finales de un libro en proceso. 


\section{Aspectos teóricos}

Un fantasma recorre el mundo: la informalidad. Esta práctica económica de actuar por fuera de reglamentos y leyes, definida así a partir de una experiencia africana en la década de 1970, y prontamente adoptada en América Latina, muestra hoy su presencia en el propio mundo industrializado a juzgar por estudios como los de Saskia Sassen (2003) que muestran que la informalidad se extiende a Europa y Estados Unidos de Norteamérica.

Las diversas posturas teóricas a la informalidad podrían agruparse en dos, estructurales (Portes, 1995) e institucionales (De Soto, 1990), por el ámbito de fenómenos explicativos que convocan, unas orientadas a la "estructura económica y social» y otras enfocadas más bien en los costos de las leyes y de los trámites, en una perspectiva neoliberal. No obstante, tienen como punto en común que la definición misma de lo informal, la línea que divide lo formal de lo informal, es el quiebre de la ley. En un caso, los «estructuralistas», entienden al Estado permitiendo procesos de acumulación capitalistas, explotadores y expoliadores y, en el otro, los institucionalistas pensando que las altas vallas del derecho constriñen a mercados, empresas e individuos.

Desde una perspectiva sociológica, hay una tendencia a observar los fenómenos sociales desde las coordenadas estructurales, y este es mi punto de vista. La configuración de la economía de un país (industrial, extractiva), los procesos de acumulación del capital, sus clases sociales, las orientaciones de clase del Estado (gobiernos plutocráticos), el nivel de educación y el capital humano de la población, el número de la población laboral empleada adecuadamente y de la informal, en la que no se cumplen legislaciones protectoras, entre otros, son los aspectos claves que explican la informalidad.

Dicho esto, no se puede negar el papel que corresponde al Estado en la configuración de la informalidad, sea concebido como producto del conflicto social (Poulantzas, 1979) o como la plasmación de una dimensión valorativa de la sociedad deseada (Aguilar, 2013, p.91). La relación causal entre el Estado y la informalidad, se expone en las políticas públicas, entendidas como la acción de gobierno, tanto en un hacer y en un «dejar hacer» (la «inacción») como en las políticas aplicadas, programas, proyectos y dispositivos «secundarios» de administración.

\section{La informalidad es el quiebre de la ley}

Las aproximaciones conceptuales a la informalidad latinoamericana, tanto la laboral como urbana, la definen a partir del quiebre de la ley. Autores como Portes (1997) ubican la informalidad como un aspecto estructural del capitalismo, mientras que otros, como De Soto (1990), ubican su matriz generadora en el Estado y, en particular, en 
el derecho y sus vallas altas de acceso a la formalidad. El elemento común a estas conceptualizaciones, y en torno a las cuales puede organizarse a diversos autores, es que agentes y actores, guiados comúnmente por el interés económico, actúan al margen de la ley. En realidad, más propiamente, combinan actividades entre lo legal y lo ilegal, es decir, adoptan un comportamiento espiral, permaneciendo o cruzando la valla legal de acuerdo a su interés.

Existen diversas prácticas en las ciudades de este comportamiento espiral de agentes y actores. Uno muy común, extendido a diversas clases sociales, son los «condominios cerrados» en su tipo de colocación de rejas que cierran calles para la seguridad ciudadana. Los mismos actores que cierran calles e impiden el libre tránsito a los ciudadanos y al espacio público — los vecinos y sus organizaciones—, a su vez, integran los comités de seguridad ciudadana, oficialmente reconocidos, y forman parte del registro de municipal de organizaciones sociales. Su búsqueda de la seguridad ciudadana los lleva a moverse entre los mecanismos legales y, a la vez, violar otros ordenamientos legales. Otro comportamiento, más común, aunque generalmente constreñido a los sectores de bajos ingresos, es el acceso ilegal al suelo urbano (a través de invasiones o mercados ilegales de tierras) el cual se combina con el recurso a diversos mecanismos establecidos por ley que otorgan al actor cierta aire de legalidad (por ejemplo, obtener la constancia municipal de posesión, estar inscrito en el registro municipal de organizaciones sociales, entre otros). Se podría extender estas prácticas a la «autoconstrucción» de las viviendas populares, la provisión no legal de servicios como el agua potable, el transporte público de pasajeros, etcétera.

Mientras que en la informalidad laboral se tiende a adjudicar la responsabilidad de la informalidad a empresas que no cumplen los rigores de la ley, en la informalidad urbana se tiende a considerar a los propios sujetos sociales (los pobladores) como quebrantadores de la ley para acceder al suelo, construir una casa, prestar un servicio o desarrollar una industria.

\section{La informalidad no es solo el quiebre de la ley}

La informalidad urbana al centrarse en el sujeto de la acción (actor o agente), pierde capacidad explicativa al no dar cuenta de la propia dinámica en la esfera estatal, sea como un ente pasivo o (re) activo. La consideración del Estado para comprender la informalidad debe partir del principio que la propia definición de informal proviene del Estado, es decir, de leyes y dispositivos administrativos que se vulneran. Esta vulneración define un aspecto de la realidad, cual es el orden de fenómenos que denominamos la informalidad, al menos como objeto de representación del observador. A través del parámetro de la ley se registran o establecen unas prácticas como formales, y otras como informa- 
les. Surgen aquí distintas interrogantes que plantea el estudio de la informalidad «en movimiento»: ¿el Estado expide leyes como un mero receptor de las demandas de los sujetos?, o más bien, ¿constituyen estas leyes el resultado de un juego o negociación (de valores) entre Estado y pobladores, e incluso fruto de relaciones de patrón/ clientela? ¿El juego y negociación definen y mueven los parámetros legales?

Un cierto consenso establece que las prácticas informales de los sujetos sociales, demandantes de derechos, obtienen concesiones o avances en el Estado (el derecho), siendo este un actor receptor de demandas a las cuales responde, concede o cede. En esta interpretación, se subraya el tránsito de una situación a otra que va desde una situación informal a otra formal (la "formalización»). ¿Cómo se expide la ley? ¿Cómo se da el continuum entre lo formal e informal? La ley es una delgada línea que convierte en movedizo el parteaguas definidor de la informalidad. En el marco de presiones y negociaciones, el Estado puede mantener las leyes ceñidas al urbanismo moderno y al código napoleónico sobre la propiedad y abre el campo a la informalidad. O puede operar a través de un «estado de excepción» estableciendo concesiones (políticas de regularización y mejoramiento) que cambian (amplían) la ley y, con ello, paradójicamente, también abre campo a la informalidad. De modo inverso, una práctica económica y social no penada (ofertar fraccionamientos urbanos sin servicios básicos, por ejemplo) puede pasar a ser ilegal si una ley la sanciona.

\section{Las políticas de vivienda en el Perú}

Los programas de ajuste neoliberal promovidos por el Consenso de Washington plantearon soluciones a los estados latinoamericanos para resolver la crisis fiscal, así como proceder a la reforma administrativa, la cual resultaba siendo un blanco fácil para las evaluaciones críticas. En la década de 1990, a través de la contención del gasto público, el Estado empezó a desprenderse de instancias consideradas innecesarias, a la vez que se promovía que fortaleciera sus posiciones en sectores considerados válidos. El gobierno de Fujimori adoptó estas políticas de ajuste económico, a pesar que su triunfo electoral se debió a la promesa de no aplicarlas, y en el ámbito de la política social favoreció a los sectores de educación y salud, en los que se asumía una "deuda social con los pobres», a la vez que se desapareció otros sectores considerados innecesarios. Este fue el caso del sector vivienda cuya política desarrollada desde inicios de la década de 1960 fue desmantelada, eliminándose, en 1992, el Ministerio de Vivienda, el sistema mutual, el Banco de la Vivienda del Perú y el sistema nacional de planificación, entre otros.

Las decisiones de política pública fueron adoptadas de manera elitista, sin considerar a la sociedad, dado que se asumía que las autoridades y sus asesores sabían lo que hacían. En el caso del sector vivienda, a la necesidad de reducción del aparato de Estado, 
se añadió la profunda convicción que el mercado era la solución a la problemática habitacional. Los policy makers pensaban que, efectivamente, el mercado suelto a sus anchas iba a resolver los problemas de la vivienda («el mercado como solución»). Por eso, una vez afirmado el régimen autoritario hacia 1992, se dieron medidas "liberalizadoras» tales como la Ley de Tierras (1995) que retiraba cualquier obstáculo al emprendimiento de los propietarios (como la protección de áreas de intangibilidad agrícola) y la Ley de Comunidades Campesinas de la Costa (1997), la cual permitía a los comuneros vender sus tierras, previo acuerdo, retirando la condición de inalienabilidad.

Esta apuesta de la política pública resultó fallida en su núcleo central porque la «liberalización» de agentes económicos no generó la esperada (gran) inversión privada en vivienda. Como correlato, se produjo el incesante incremento del déficit de vivienda en el nivel nacional y el crecimiento de la informalidad urbana. En 1990 el déficit era de 745,079 unidades de vivienda, en 1995 había subido a 892,744 viviendas y, en 1999, había cruzado la barrera del millón de unidades de déficit (Ccancre, 2016, p.86; sobre datos de INEI-CAPECO área estadística, pp. 86).

En la informalidad urbana, Calderón (2006, p.102) estimó que en Lima entre 1993 y 1998 las barriadas pasaron de 1,147 a 1980, y su población de 2.188 millones a 2.623 millones, lo cual quiere decir que entre 1993 y 1998, los ańos de la fase dura del neoliberalismo, 72,500 personas cada año fueron a vivir a una barriada. Hacia el 2002 sumaban 3,653 barriadas en Lima con 3.8 millones. A partir de 1992, el crecimiento de las barriadas había devenido en caótico por la falta de una política de vivienda y el retiro de programas ordenados de acceso al suelo; y los pobres ocupaban rellenos sanitarios, cerros de difícil topografía ubicados en áreas de riesgo, y cobraban fuerza los mercados pirata informales, hoy llamados «tráfico de lotes». La situación empeoró cuando el propio gobierno se abocó, en el camino de la reelección del año 2000, a promover invasiones de tierras para obtener clientelas (Oasis de Villa El Salvador, zona agropecuaria de VES y Rinconada), la segunda de las cuales llevaría, por la reubicación aplicada a un mayor poblamiento de Ventanilla (zona de Pachacutec, Profam).

En la década de 1990 la informalidad urbana creció a un ritmo mucho mayor que en los años previos al neoliberalismo. Pero esto no ocurrió, como plantea el discurso liberal, porque el Estado hubiera puesto muchas vallas y trámites a los mercados desde una perspectiva estatista. Por el contrario, se habían eliminado subsidios y programas públicos de vivienda (sistema mutual, acceso ordenado al suelo) y se había liberado a los propietarios de tierras de constreñimientos reguladores. Lo que sí podría argumentarse es que la combinación de populismo y neoliberalismo bajo un régimen autoritario acentuó la tendencia a promover soluciones informales para obtener la legitimidad de las masas.

Los resultados negativos de la política restringieron en Lima a una producción de solo 6,000 unidades en distritos de clase media alta. En el marco de protestas, por 
ejemplo de los contribuyentes al Fondo Nacional de la Vivienda (FONAVI), que sentían que su contribución no generaba unidades de vivienda, la Cámara Peruana de la Construcción (CAPECO) reclamó el otorgamiento de subsidios, palabra hasta entonces considerada tabú por el régimen neoliberal, pero que, por esos años, en el «exitoso modelo chileno», llevaba a la construcción de 150 mil viviendas por año:

CAPECO postula el establecimiento de una política de mediano y largo plazo, a través de un subsidio transparente y directo a la demanda, relegando de manera definitiva los subsidios indirectos o encubiertos a la oferta, a fin de dotar al país de 80,000 unidades de vivienda anuales... en base a la conjunción de recursos del sector privado, ahorro familiar y subsidios estatal (CAPECO, Propuesta de politica de vivienda, junio de 1996).

Como respuesta, en 1997, se creó el Fondo Mi Vivienda (FMV), siendo reglamentada al año 1998. Un fondo que operaría a través del «modelo $A B C$ »: ahorro (de la demanda), bono o subsidio otorgado por el Estado y crédito, a ser otorgado por el Estado a través de la banca privada.

En el siglo xxI, recuperada la democracia representativa, el gobierno de Alejandro Toledo (2001-2006) fue muy crítico con la política anterior:

A partir de 1991, se inició el proceso de debilitamiento institucional del sector vivienda, cuyos principales hitos fueron:

a. Una merma notoria de influencia política y recursos económicos...

b. El mal uso y posterior liquidación del Fondo Nacional de Vivienda...

c. La liquidación de las entidades que brindaban el financiamiento hipotecario para las familias de estratos medios y bajos...

d. La dispersión, en diferentes instancias del aparato estatal, de las entidades encargadas de la instrumentación de políticas...». (MVCS, 2006, p. 3)

Si bien el gobierno de Toledo continuó con la política de corte neoliberal, reconstruyó el sector vivienda. El FMV tuvo impacto a partir del 2002 tras una serie de arreglos institucionales solicitados por los constructores, especialmente, la elevación del bono/ subsidio para hacer frente al costo del precio del suelo (Calderón, 2009). Ese mismo año, el gobierno de Toledo creó el Programa Techo Propio para direccionarlo a los sectores de menores ingresos, con tres modalidades, entre ellas Adquisición de Vivienda Nueva (AVN) y Construcción en Sitio Propio (CSP).

Techo Propio realmente cobró impulso con el segundo gobierno de Alan García (2006-2011), el cual sostenía que ya se había apoyado a la clase media con el FMV y que era necesario reorientar la inversión. Más aún, con el de Ollanta Humala (20112016) cuando Construcción en Sitio Propio (CSP) alcanzó, en el 2015, los 45000 bo- 
nos. Entre 2003 y 2017 Adquisición de Vivienda Nueva (AVN) otorgó 46,376 bonos y Construcción en Sitio Propio (CSP) unos 228127 bonos. Por su parte, el FMV, que pasó a llamarse Nuevo Crédito Mi Vivienda (NCMV), otorgó 106526 bonos, aunque recibió el $80 \%$ de la inversión del sector en vivienda, ratificando la tendencia estatal a apoyar la vivienda de la clase media, en la cual sector privado encuentra una mayor rentabilidad (Calderón, 2015).

El giro en la orientación de los bonos de vivienda hacia los sectores de menores ingresos representó algunos cambios en la política de vivienda, aunque es cierto que frente a la demanda cuantitativa de vivienda AVN tuvo un débil desempeño, alcanzando un $30 \%$ de sus metas sobre 150,000 unidades nuevas esperadas. Esta modalidad no pudo superar el escollo del incremento de los precios del suelo (Calderón, 2015) y, finalmente, solo absorbió al 2017 el 11.7\% del déficit de vivienda definido a partir del censo del 2007 (MVCS, 2018). Por su parte, CSP se dirigió a la demanda cualitativa, la cual ya tenía terreno, y llegó a cubrir el 15.4\% del déficit al 2017 (MVCS, 2018).

La modalidad del bono CSP se otorgaba a la población que había accedido a su vivienda mediante la informalidad y contaba con título de propiedad otorgado por COFOPRI y factibilidad de servicios básicos. La puesta en operación del bono (subsidio), véase la siguiente sección, significó, a partir del 2002, que el Estado limaba su propia propuesta de titulación, hasta entonces basada en los mecanismos del mercado, por la cual el poblador que había sido informal, con su título de propiedad en la mano, debía hipotecar su propiedad para construir su vivienda.

Fueron los primeros ańos del siglo xxi de ventura para el Perú debido a que el Producto Bruto Interno creció, animado por el empuje de la economía china, y el boom de la construcción (2002-2012). La pobreza se redujo drásticamente (apoyada por una nueva medición estatal basada en la pobreza monetaria), la clase media emergente creció, los ingresos se elevaron y el país pasó a ser considerado uno de «ingresos medios», con lo cual la cooperación internacional inició su retirada y desplazamiento hacia países pobres (Bolivia, Haití). Observado desde el ángulo de la informalidad, el panorama no resulta tan alentador. La informalidad laboral se mantuvo en un 70\% de la Población Económicamente Activa (PEA) y la informalidad urbana explosionó, constituyendo un resultado paradójico frente al crecimiento económico. Según información del sector público, las barriadas (denominados Barrios Urbano Marginales, BUM) en el nivel nacional pasaron de 7419 en el 2002 a 8940 en el 2007 y su población de 7717336 a 7642658 habitantes, observando un ligero descenso. Pero en Lima, los BUM pasaron de 2705 en el 2002 a 4453 en el 2007, se duplicaron, y la población, en ese mismo lapso, pasó de 2072245 a 4105884 habitantes (MVCS, 2005 y 2014).

Una explicación de por qué en el marco de un crecimiento económico (un crecimiento del PBI a tasa promedio de 4.8\% entre 1990 y 2010 y un ingreso per cápita que pasó de US\$ 3241 a US\$ 9281) se incrementó la informalidad urbana tiene que 
ver con limitaciones de la estructura económica y social. Desde la acción de gobierno (política pública), la inversión pública en vivienda fue insuficiente para reducir el déficit en vivienda, no tuvo el acompañamiento esperado de la inversión privada y se orientó a acciones curativas frente a la informalidad urbana y no a generar nuevas unidades de vivienda para evitarla.

El modelo de articulación público/ privado falló y, siendo el punto que orienta este artículo, las propias políticas públicas, expresadas en valoraciones (leyes) y aspectos factuales (técnicas, administración), estimularon antes que contuvieron la informalidad urbana. Ni bajo la etapa del «mercado como solución» (década de 1990) ni en la de la orientación a la demanda (modelo ahorro, bono y crédito del siglo xxi) la acción de gobierno pudo frenar la informalidad urbana, especialmente en Lima.

Este resultado no puede atribuirse a las «altas vallas» del Estado, o a constreńimientos públicos a la inversión privada. Los mercados operaron en un laissez faire y, luego, el Estado, en su rol facilitador de la inversión privada, brindó un subsidio dejando las soluciones a la articulación entre los mercados de vivienda y de suelo, sin que hubiera creado o puesto en práctica instrumentos reguladores de gestión del suelo. Durante estos ańos, los empresarios organizados en la CAPECO no dejaron de demandar del Estado suelo barato, mayores montos de subsidio y una política de dotación de agua potable que asegurara una expansión de las urbanizaciones formales. La única crítica vinculada a las vallas del Estado se dirigió a los engorrosos trámites de las municipalidades para las habilitaciones urbanas, por lo cual cabe preguntarse si una política en este sentido hubiera generado una baja de precio de las viviendas de modo que evitaran la proliferación de la informalidad urbana.

\section{Las políticas de titulación de la propiedad}

En 1996 la política de regularización de la tenencia de la tierra se orientó hacia la promoción del uso de los derechos de propiedad, bajo el supuesto de que la informalidad se origina por el peso del derecho formal que crea barreras procedimentales para los pobres, imposibilitándolos de aprovechar el valor de sus propiedades (De Soto, 1990). El Decreto Legislativo No 803, «Ley de Promoción de Acceso a la Propiedad Formal» de 1996, despojó a las municipalidades distritales de su función de titular y creó la Comisión de Formalización de la Propiedad Informal (COFOPRI).

Se trató de una política diseñada de manera elitista, incluso con un programa piloto desarrollado en 1990-1992 que no se hizo de conocimiento público (Morris, sin fecha), y que fuera formulada por funcionarios que, a partir de un constructo, pensaron que la titulación produciría una mejora de la economía y de los pobres urbanos. El decreto legislativo 803 afirmó la idea de la propiedad como el mayor valor de los pobres: «La 
propiedad predial constituye la mayor parte de los activos de los peruanos de menores recursos y, sin embargo, no puede ser utilizada en el mercado legal pues carece de un título debidamente registrado que le confiera valor de intercambio».

La política planteó que, con la formalización, se incorporarían los activos a una "economía social de mercado", generándose el incremento del valor de los predios de los peruanos de menores recursos y, finalmente, que la población ya no recurrirá a la invasión y al acceso extra legal. Pocas políticas encajaban a la perfección con las propuestas neoliberales, debido a su énfasis en los derechos de propiedad privada, complementado con el anhelo de la Constitución de 1993 de un Estado promotor de los negocios privados, que favoreciera fuertes derechos de propiedad privada individual, leyes e instituciones del libre mercado y el libre comercio. Se esperaba que la política activaría supuestos trillones de dólares que los pobres urbanos tenían acumulados en sus predios y viviendas, un capital muerto que yacía en sus entrañas sin que el Estado o el mercado se hubieran percatado (De Soto, 2000). Se asumía a los pobres, como en general a todos los individuos, como racionales y buscadores de utilidades.

La política de formalización planteó dos ejes para enfrentar a la informalidad. Uno era formalizar las posesiones informales que, de este modo, se incorporarían a la economía formal. El otro eje, contenido en el título III del D.L. 803, autorizaba a la COFOPRI a establecer un inventario de terrenos estatales con el objetivo de promover vivienda a los sectores de menores ingresos y frenar, de esta manera, la formación de posesiones informales. En su diseño la ley contenía lógica: formalizar lo informal y prevenir la informalidad a través de la promoción de vivienda para los pobres.

La implementación de la política, no obstante, pronto priorizó el eje de la titulación y dejó de lado la acción preventiva frente a la informalidad. Entre 1996 y 2000, durante el gobierno de Fujimori, se distribuyeron 1049134 títulos de propiedad a los habitantes de los asentamientos precarios, de los cuales unos 547064 correspondieron a Lima. El Proyecto de Derechos de Propiedad Urbana (PDPU), apoyado por el Banco Mundial, puso el énfasis en la distribución de los títulos en la idea que permitiría a los pobres obtener provechos económicos y sociales a través de la seguridad de tenencia, el acceso al crédito de la banca privada y el desarrollo de mercados inmobiliarios seguros. Adicionalmente, la masiva titulación, la cual se nutrió de la explosión de barriadas que la falta de una política de vivienda por su parte generaba, fue utilizada para los fines políticos de la relección de Alberto Fujimori en el 2000, revelando el carácter populista neoliberal del régimen.

La política estableció una nueva secuencia para el desarrollo urbano de dichos asentamientos. Mientras la política de regularización de 1961 definió que el título de propiedad era la etapa final del proceso de regularización — posterior al reconocimiento de la ocupación y la dotación de servicios básicos- el Decreto Legislativo No 803 
constituyó al título de propiedad como un paso obligado para la obtención de dichos servicios.

El eje preventivo que establecía viviendas para los pobres fue dejado de lado. El D.S. 009-99 del Ministerio de Transportes y Comunicaciones (MTC), de 1999, establecía que sólo COFOPRI podía desarrollar programas de adjudicación de lotes, tener un patrón de solicitantes y adjudicar tierras eriazas y ribereñas en favor de entidades municipales, públicas o particulares; para lo cual se derogaron las competencias municipales en la materia y se frenó aislados esfuerzos municipales por promover programas de acceso al suelo y / o vivienda (Trujillo, Ilo). COFOPRI no avanzó en esta materia, salvo en el 2000, cuando el régimen, tras promover invasiones de tierras, armó a toda prisa el Programa Lote Familiar (PROFAM), destinado a reubicar a los invasores, pero más con fines electorales. ${ }^{2}$

Por otro lado, la legislación buscó otorgar préstamos a los invasores de tierras privadas para que paguen por los terrenos a los propietarios afectados. Una primera tentativa se produjo en 1999 cuando la ley 27136 estipuló que el sector público diera créditos a los ocupantes para que salden la deuda por el valor del terreno. Esta ley fue rechazada por los poseedores y no tuvo aplicación real. En el 2004, en la vía de la conciliación entre los ocupantes de los predios y los propietarios, la ley 21938 estableció que las municipalidades provinciales podían propiciar procesos de conciliación. Posteriormente, también se reveló inútil la ley 28687 del 2006 que añadía instrumentos como la permuta de terrenos, entre otros.

Con el gobierno de Toledo (2001-2006), se distribuyeron unos 495018 títulos, de los cuales en Lima unos 113665 títulos. Bajo el segundo gobierno de García (20062011), una fuente indicaba 543457 títulos en el nivel nacional, de los cuales 68696 correspondieron a Lima y Callao, con lo cual continuó descendiendo la distribución en la gran metrópoli (Perú, 2011). Entre agosto de 2011 y agosto de 2016 (gobierno de Humala) se formalizaron 374849 lotes/ predios (MVCS, 2018). En total, entre 19962017 se habrían otorgado unos 2.4 millones de títulos.

En forma paralela a la titulación, continuó la tradición del derecho urbano peruano de aplicar sucesivas amnistías a los invasores de tierras. Con el gobierno de Alberto Fujimori se tuvo la ley 26264 de 1993 y el decreto legislativo 803 de 1996. Posteriormente, con el gobierno de Alejandro Toledo, el decreto supremo 021 del Ministerio de Justicia de junio del 2002 y la ley 28391 de noviembre de 2004. Finalmente, con el gobierno de Ollanta Humala el decreto legislativo 1202 de septiembre de 2015. Estos dispositivos continuaron alimentando en los pobres la expectativa que la informalidad urbana consistía, realmente, el medio de atender al problema de la vivienda.

2 En julio del 2001 el decreto supremo 038-2001 del Ministerio de Transportes y Comunicaciones cuestionó y desactivó la experiencia del PROFAM, tildándola de un programa de «adjudicación de lotes tizados en áreas alejadas», creando en su lugar el Programa Mi Barrio. 
La mayoría de los resultados esperados por la titulación no se dieron. Falló el supuesto que los títulos permitirían a los pobres el acceso a créditos de los bancos privados, por medio del otorgamiento de garantías hipotecarias, con la finalidad que pusieran un negocio o construyeran la vivienda. Al 2003, solo 1.5\% de los titulados por la COFOPRI hipotecaban su vivienda. Por lo tanto, el vínculo entre propiedad formalizada y crédito formal empezó a ser dejado de lado y se abandonó la propuesta del Centro de Información Positiva sobre el comportamiento crediticio de los pobres, aunque no el discurso justificativo que se mantuvo algún tiempo después. El puntillazo final sobrevino cuando el Programa Construcción en Sitio Propio (2002) empezó a otorgar un subsidio para construir la vivienda a los titulados por la COFOPRI, con lo cual se abandonaba la idea que los titulados recurrieran a la banca privada para construir sus viviendas. Tampoco la titulación consolidó los mercados inmobiliarios formales o generó el pago de los impuestos prediales que hubieran aumentado la recaudación de los gobiernos locales (ESAN-IMASEN, 2004; Calderón, 2011).

Más bien la política de titulación empezó a mostrar sus resultados negativos. Uno los más graves fue titular predios ubicados en áreas de riesgo, tal como en "Pisco Playa», o en los cerros de Independencia y Comas (Reyes, 2010). Hacia el 2006, se estimaba que la mayoría de los «asentamientos humanos» se ubicaban en zonas de riesgo. De cada 100 asentamientos programados para la formalización, según la Oficina de Desarrollo urbano de la Municipalidad Metropolitana de Lima (MML), entre 80 a 90 se encontraban en zonas de riesgo, debiendo generarse articulaciones entre la COFOPRI, la MML y el Instituto Nacional de Defensa Civil (INDECI) (Reyes, 2010, p. 37).

La titulación promovió un mayor individualismo, una reducción del comunitarismo y una afectación de la organización social (Ramírez \& Riofrío, 2006). Por el carácter defendible de los derechos de propiedad otorgados, además de definible y enajenable, los titulares de la propiedad podían habitar su propiedad, venderla o alquilarla informalmente, o dejarla vacante en ejercicio de sus derechos plenos, sin que hubiera control comunal o vecinal sobre ellos. Se desplegó una especulación con los lotes a escala micro, tal como lo muestra el $20 \%$ o $30 \%$ de lotes vacantes en los asentamientos formados desde la década de 1990. El valor de los predios se elevó, pero se trató de una buena noticia para el vendedor pero no para el comprador o inquilino. Al subir los precios de venta o alquiler de la vivienda titulada, los más pobres tuvieron que continuar invadiendo en zonas agrestes o áreas de riesgo, recurriendo a los cuartos de alquiler, o peor aún, caer en manos de los mercados ilegales de tierras que empezaron a florecer.

En conclusión, la titulación no redujo la informalidad urbana. Mientras que al 2000 se habían otorgado un millón de títulos de propiedad, en el ámbito urbano nacional faltaba formalizar 820,00 predios más (García, 2002, p. 32). En el 2017, con unos 2.4 millones de títulos acumulados, se estimaba una demanda efectiva restante de 
1515151 predios/ lotes (MVCS, 2018). Mientras los gobiernos distribuían más títulos de propiedad, se alimentaban las expectativas por la ocupación informal.

La titulación sin una contraparte en programas de vivienda y suelo urbano genera el circulo vicioso de la informalidad ${ }^{3}$ : En la medida que los gobiernos se limitan a otorgar títulos de propiedad o proveer servicios básicos, sin a la vez generar viviendas nuevas o programas de acceso ordenado y formal al suelo, la población pobre alimenta sus expectativas por la regularización y el mejoramiento y continúa invadiendo o adquiriendo en los mercados ilegales de tierras. Los programas curativos tienen el efecto indeseado de estimular nuevas ocupaciones informales. Por otro lado, las medidas preventivas del D.L. 803 sobre programas de vivienda no se desarrollaron porque los ejecutores optaron por la simple distribución de títulos, una actividad más barata y políticamente rentable.

\section{Las constancias municipales de posesión}

Las constancias o certificados de posesión otorgados por la municipalidad, establecidos en el 2006, tuvieron como propósito permitir a las poblaciones informales el acceso a los servicios básicos, lo cual resultaba dificultado porque la política de titulación implementada desde 1996 había alterado la secuencia del desarrollo urbano no planeado establecida por la ley 13517 de 1961. De acuerdo a la ley de 1961, el título de propiedad era el final de un camino en el que primero se proveían los servicios, pero la política de titulación a partir de 1996 imponía al título como uno de los primeros pasos y requisito esencial para la provisión de servicios. Por diversas razones (invasores no amnistiados, indefinición de la propiedad, demoras burocráticas) se había formado una demanda por servicios bloqueada por la ley existente.

Las constancias o certificados fueron establecidas por la Ley de desarrollo y complementaria de formalización de la propiedad informal, acceso al suelo y dotación de servicios básicos, número 28687, en febrero del 2006. Posteriormente, el reglamento (decreto supremo No 006-2006-Vivienda), en marzo de 2006, establecería que las pruebas de posesión remitirían al artículo 38 del D.S. 013-99-MTC, el cual considera, entre otras, los contratos de préstamos celebrados entre el poseedor con instituciones públicas o privadas, recibos de pago por servicios de agua, luz u otros, declaraciones juradas de pago al Impuesto al Valor del Patrimonio Predial, certificados domiciliarios expedidos por el juez de Paz o la policía.

En apariencia, los certificados o constancias enmendaban, dentro de una perspectiva incremental de la política pública, una deficiencia o vacío que había dado lugar a me-

3 La expresión y la idea que contiene el círculo vicioso de la informalidad me fueron indicadas por el Arq. Mario Lungo en una reunión de profesores del Lincoln Institute of Land Policy en El Salvador hacia 1997. 
canismos de conflicto, presión y negociación entre los pobladores de los «asentamientos humanos», el gobierno nacional e incluso las empresas proveedoras de servicios de agua y luz eléctrica. Decenas de miles de pobladores informales bloqueaban carreteras, desarrollaban marchas y enfrentamientos. Las empresas proveedoras de servicios también vieron afectados sus intereses por no poder avanzar con políticas de extensión de redes. A diferencia de las anteriores políticas, cuyo diseño había sido elitista, en este caso el instrumento de la constancia municipal era una respuesta a la presión social, y podía presumirse que su aplicación resolvía un indeseado cuello de botella

Este ańadido a la política de titulación, sin embargo, terminó generando, tal como había ocurrido con las otras dos políticas expuestas, una mayor informalidad; solo que ahora asociada a la economía delictual (un fenómeno denominado en el Perú como «tráfico de lotes»). Se produjo un desencuentro entre la intención del gobernante a la hora de expedir una ley y sus consecuencias. La explicación de cómo una política destinada a mejorar la calidad de vida de la población informal, y que no implicaba una transferencia de dominio de la autoridad municipal, contribuyó a una mayor informalidad debe buscarse en el campo poco estudiado de la aplicación de las «normas secundarias» (los aspectos factuales de la política), aquellas que conciernen a la administración operativa y que implican una diversidad de instrumentos (decretos y resoluciones supremas, ordenanzas municipales, actos administrativos, etcétera).

La ley 28687 devuelve a las municipalidades un rol en la titulación, sumado al de la facultad de poder celebrar los convenios con la COFOPRI establecido desde el 2001. La constancia, más allá de no implicar la transferencia de dominio, en la práctica se configura como un instrumento jurídico en medio de la posesión de facto y la propiedad. Las municipalidades, en virtud de la autonomía que le otorga su ley orgánica, tienen la potestad de definir los aspectos operativos del otorgamiento de las constancias, a través de las normas estipuladas en Texto Único de Procedimiento Administrativos (TUPAs). Las municipalidades pueden decidir la unidad administrativa dentro del aparato municipal que gestiona los certificados o constancias, así como si la unidad de demanda es un posesionario individual o un grupo colectivo, el costo del certificado, los requisitos en general, etcétera.

Esta autonomía en los instrumentos de actuación permite a las autoridades municipales insertar los certificados en su estrategia política, y en las propias interacciones que en el espacio local desarrollan con los diferentes agentes y actores. En un sentido realista, que escapa por tanto a los comunes discursos prescriptivos de los estudios sobre las políticas públicas, las autoridades municipales pueden desarrollar un juego de interacciones en función de estrategias clientelares o, más llanamente, de conveniencia económica. Adicionalmente, el certificado o constancia pasa a formar parte de una estrategia municipal junto con otros instrumentos o bienes que poseen, tales como reconocimiento de organizaciones sociales, provisión de alimentos a través del Programa 
del Vaso de Leche, visado y aprobación de planos de los asentamientos, etcétera. El uso del certificado pasa a ser parte de un juego de reglas de uso previstas y no previstas, negociaciones y resultados y, por lo tanto, a insertarse en la propia mecánica espiral que caracteriza a la informalidad urbana.

Un ejemplo de la consecuencia de esta utilización de los certificados de posesión municipal en forma no prevista por la autoridad, y que ha alcanzado inclusive características delictivas, es el aumento de los mercados informales de tierras.

\section{Predominio de mercados informales de tierras sobre las invasiones}

Una característica en el nivel mundial es la mercantilización de los canales de acceso al suelo y a la vivienda para los sectores de menores ingresos, como han mostrado los procesos privatización de la vivienda social en Europa Occidental y Europa Oriental. En el Perú, años atrás, predominaban en las ciudades peruanas, especialmente las costeras, mecanismos de invasiones de tierras, los cuales calzaban en la figura de delito de usurpación, pero que fueron tolerados por las autoridades en tanto tácitamente se reconocía que ni el mercado inmobiliario formal ni el Estado tenían alternativas que ofrecer. Es relativamente reciente el hecho que los mecanismos informales de mercado de suelo hayan venido reemplazando a las invasiones.

De modo contrario a las políticas propuestas por los policy makers, la «liberación» del suelo de los constreńimientos institucionales y el reforzamiento de la propiedad privada (ley de tierras de 1995, ley de titulación de 1996, ley de comunidades campesinas de la costa de 1997, entre otras), no promovió una inversión privada formal sino más bien una informal y delictiva. Se desplegaron (sub) mercados informales de tierras en diversas modalidades, siendo las principales la venta a sectores de menores ingresos de tierra pública usurpada, la venta de tierra por dirigentes de las comunidades campesinas de la costa, las ventas de pequeños propietarios beneficiarios de la reforma agraria y las ventas micro por parte de familias populares. ${ }^{4}$

La venta de tierra pública usurpada por mafias delincuenciales a sectores de menores ingresos es hoy un fenómeno de conocimiento público, ampliamente difundido. Una nota periodística resume bien esta modalidad:

Todo empieza con bandas delictivas que identifican amplios terrenos de propiedad del Estado. Luego buscan llegar a las autoridades ediles que los administran. Invaden las zonas y construyen allí algunos predios de material noble. Con los contactos hechos

4 Este artículo no considera la venta por funcionarios públicos corruptos de tierra pública, tal como las protagonizadas por funcionarios de COFOPRI hacia los años 2010 y 2011 bajo el gobierno del APRA en el distrito de Chilca. 
en los municipios, los invasores obtienen constancias que los acreditan como antiguos posesionarios. Las mafias utilizan rótulos de asociaciones de vivienda e incluso se inscriben en registros públicos (El Comercio 10 de febrero de 2018, p. 10)

De manera que el amplio stock de tierra pública en el Perú, el cual podría ser utilizado para vivienda social, y que fuera dejado de lado por la política neoliberal que define que las soluciones deben provenir de la iniciativa privada, ha dado pie al surgimiento de mafias organizadas que la invaden bajo la figura de Asociaciones de Vivienda, lotizan y venden a una demanda de menores ingresos. Estos procesos ocurren, en Lima, en los distritos de Cieneguilla, Ventanilla, Santa Rosa, Carabayllo, San Juan de Lurigancho, entre otros.

La mafia, por lo común asociada a los alcaldes, involucra a diversos actores, tales como:

- Financistas, cuyo dinero proviene originalmente de la extorsión a empresas constructoras formales $\mathrm{u}$ otras formas delictuales.

- Usurpadores, grupos de maleantes, y a veces de pobladores sin techo, que constituyen la invasión inicial sobre el terreno.

- Creación de la «asociación de vivienda», e inscripción en registros públicos de la misma.

- Constructores, quienes instalan módulos prefabricados y de material noble para acreditar la vivencia y antigüedad del lugar.

- Vendedoras, quienes ofertan los lotes, reclutando compradores, denominados «socios» y hacen publicidad de las ventas "cara a cara» y por otros medios.

- «Brazo armado», el cual mantiene la seguridad del terreno usurpado, evita que otros invasores arrebaten esos predios y "pone en regla» a compradores que se consideren estafados.

- Alcaldes que expiden constancias de posesión municipal o permiten la usurpación de los terrenos públicos o de comunidades campesinas, colaboran con visado de planos perimétricos, memorias descriptivas, constancias de pago de arbitrios y resoluciones de gerencias trucadas.

Funcionarios públicos corruptos de la Policía Nacional del Perú, quienes ignoran los crímenes, no registran los delitos y alertan a los promotores de intervenciones de la fuerza pública; funcionarios de la Superintendencia de Bienes Nacionales (SBN) o de la COFOPRI, quienes seleccionan los terrenos públicos poco protegidos o facilitaban conciliaciones extrajudiciales.

Abogados, quienes ejercen la defensa de los promotores inmobiliarios (Fuente: El Comercio, ediciones del 4 y el 10 de febrero de 2018).

La práctica de las mafias delictuales les reporta grandes ganancias. Se ha estimado en la ciudad de Trujillo, en la cual 10 bandas criminales se disputan las tierras, que la 
venta de un «barrio» (de una extensión de 12 hectáreas) permite una ganancia de 10 millones de soles, lo cual equivalía a 3.3 millones de dólares USA.

Las comunidades campesinas en el Perú, según el III Censo Nacional Agropecuario de 1994, poseían el 40\% del total de las superficies de las unidades agropecuarias del Perú. A pesar que la Constitución de 1933 consideró las tierras comunales inalienables, imprescriptibles e inembargables, la Constitución neoliberal de 1993 retiró las dos primeras consideraciones y, en 1995, la Ley de Tierras facilitó la venta de tierras comunales y, en 1997, la Ley de Titulación de las Tierras de Comunidades Campesinas (CC) de la Costa, número 26485, autorizó a los comuneros a vender sus tierras siempre que se contara con la anuencia de más de la mitad de los comuneros.

Nuevamente, por fuera del impacto esperado en términos de inversiones agropecuarias por el marco legal, se ha impulsado una dinámica propia en tierras comuneras no productivas ubicadas en la periferia de las ciudades. Las tierras comuneras reciben presión de promotores inmobiliarios privados, ante la cual los dirigentes de la comunidad campesina, quienes fungen de propietarios, las venden, muchas veces sin consultar a los demás socios. Mediante estas ventas ilegales se ha producido suelo para sectores de menores ingresos (como en Carabayllo o Jicamarca en Lima), aunque también para la clase media alta como aquellos terrenos de la comunidad de Asia que han cedido lugar a condominios cerrados de lujo.

Los pequeños propietarios beneficiarios de la reforma agraria en la periferia agrícola de Lima están vendiendo sus parcelas a empresas inmobiliarias. Tras el proceso de individualización de la propiedad colectiva (cooperativas agrarias), los beneficiarios de la reforma agraria adoptaron varias estrategias: arrendar la tierra, aliarse con empresas inmobiliarias externas para lotizar sus tierras agrícolas, retener suelo y retardar la venta para aumentar el precio del terreno. También hubo propietarios parceleros, empresas inversionistas e hijos de los beneficiarios que activaron la venta de suelo sin estudios técnicos para el cambio de uso de agrícola a urbana. Tanto los promotores inmobiliarios que compran las tierras, como los propios beneficiarios que se lanzan a la aventura inmobiliaria, lo hacen sin respetar los códigos de urbanización vigentes (Pimentel, 2015).

Por último, en los propios asentamientos populares, existen procesos de venta y alquiler de lotes y predios por fuera de los marcos legales. Por un lado, dirigentes que se benefician con las «ampliaciones» de los asentamientos humanos y, del otro, familias que ocupan inicialmente tierra pública apoderándose de 6 o 7 lotes, los cuales venden a lo largo del tiempo. A su vez, pobladores que se han beneficiado de un título de propiedad de la COFOPRI sin tener necesidad de una vivienda, despliegan un mercado ilegal micro de lotes. Como se afirmó: «En la inserción de las familias a los sistemas de estrategias de reproducción social, el uso y recurso, formal o informal, de la propiedad inmobiliaria, dependerá de los beneficios diferenciales que puedan esperar en función 
de los poderes efectivos de los que dispongan, los cuales se establecen de acuerdo a su volumen y estructura de capital» (Calderón, 2011, p. 53).

El paso del predominio de las invasiones a los mercados ilegales de tierras para los sectores de menores ingresos muestra cambios en los mecanismos de producción de la informalidad urbana. Esta informalidad, asociada a mecanismos mercantiles, es producto de diversos vectores, entre ellos la ideología propietarista y el individualismo promovido, entre otros, por la política de titulación, la relativa mejora de la economía peruana (surgimiento de la clase media «emergente») y las consecuencias de políticas urbanas (vivienda, titulación, «liberalización» del suelo).

\section{Conclusiones}

Este artículo buscó entender cómo la acción estatal genera la informalidad urbana y sus consecuencias. Esta intención no niega el peso de los constreñimientos estructurales para entender la informalidad. En el Perú, por ejemplo, un modelo económico extractivista limita la generación de núcleos internos de acumulación y eso impacta en la informalidad. No obstante, este artículo se ha interesado en observar la propia acción del gobierno y su efecto en la informalidad.

Las diversas modificaciones legales y económicas emprendidas por el Estado peruano no tuvieron como fin promover la informalidad urbana, sino todo lo contrario. Los gobernantes realmente pensaron que las reformas emprendidas llevarían a una mayor presencia de la (gran) empresa privada formal, el desarrollo de la economía formal, la mejora de la calidad de vida de la población, etcétera. ${ }^{5} \mathrm{El}$ asunto a explicar es por qué los resultados no acompañan a las intenciones.

El incremento o la permanencia de la informalidad urbana no obedece a que el Estado (y el derecho) hayan puesto obstáculos o vallas altas a los actores. Este artículo concluye que la propia acción de gobierno muestra que:

- Existe al interior del Estado una doble práctica, por la cual funcionarios y autoridades realizan actividades, unas ceñidas a lo formal dentro del marco legal y administrativo y otras no formales, por fuera del sistema o en el límite de ellas («zonas grises»). Esto se explica porque quienes forman parte del aparato del Estado requieren resolver nudos conflictivos difíciles de absolver en el marco jurídico y administrativo existente o, y de manera no excluyente, desarrollan intereses propios y llevan a cabo prácticas movidas por el interés económico (la

5 Existen otros países latinoamericanos en que también las medidas «liberalizadoras» en la búsqueda de la inversión privada formal han llevado a una mayor informalidad urbana. Es el caso de México y la reforma del artículo 27 de la Constitución (1992) que levantó restricciones a los ejidatarios beneficiados por la reforma agraria (Iracheta, 2015). 
corrupción), la conveniencia política (clientelismo), la búsqueda de legitimidad social, entre otras.

- En la búsqueda de legitimidad social el Estado expide leyes y dispositivos que al intentar responder a las demandas de la sociedad lo llevan a contradecir sus propias propuestas de política pública (el desencuentro entre los propósitos de la titulación y la política de vivienda a partir del 2002 es una muestra) o, inclusive, "legalizar la informalidad», es decir, adoptar dispositivos que en lugar de establecer a los parámetros urbanísticos modernos y legales de la propiedad como parteaguas de definición, empiezan a tornar legales prácticas y demandas desde abajo que, usualmente, han sido observadas como informales (es el caso de la constancia de posesión).

- La capacidad de mover o cambiar políticas y leyes es un factor determinante del continuum entre lo formal y lo informal e indica que la ley no es fija e inmutable. Se tolera, negocia o acepta presiones sobre el contenido de la ley y, por ende, se modifica la definición de la realidad, insertándola en la espiral que caracteriza la informalidad. A su vez, el Estado, más allá de actuar por fuera de la ley, puede vulnerar su propia ley (omisión de funciones).

- En el plano del discurso, la evolución de políticas públicas adaptándose a las circunstancias de la búsqueda de legitimidad social y, de manera no buscada, promoviendo la informalidad, no es motivo de reflexión sobre la propia ideología neoliberal, la cual se mantiene incólume. El hecho que diversas políticas, realmente promuevan la informalidad, no afecta el discurso de la política pública en favor del mercado y de la propiedad, y en contra de la comunidad y la acción colectiva. Por ejemplo, se siguen ensalzando los supuestos efectos pro mercado de las políticas de titulación, aunque hayan fracasado en su aplicación práctica, y se subvaloran efectos positivos de las políticas porque refieren al valor de uso y simbólico de la propiedad (y no al valor de cambio). El discurso sigue recusando a la informalidad y pensando que el libre mercado es su antídoto a pesar de los resultados empíricos.

- El mundo de la política pública en el nivel local, y la generación y aplicación de normas secundarias y dispositivos de menor rango, es el espacio ideal para que se perpetúe la informalidad asociada a la corrupción y al clientelismo por la vía de interacciones entre agentes y Estado.

En suma, no es tan sencillo pensar que la informalidad urbana pueda combatirse con el libre mercado y la desregulación, dado que el mercado, como institución, no solo condensa la acción de los agentes económicos y sus intereses privados, sino que puede tener prácticas y consecuencias distintas a las promovidas y pensadas por ideólogos y políticos y, más grave aún, afectar a la ciudad concebida como un bien común. 


\section{Referencias}

Aguilar, L. (2013). Gobernanza y gestión pública. México: FCE.

Calderón, J. (2015). Programas de vivienda social nueva y mercados de suelo en el Perú. En EURE $\mathrm{N}^{\circ}$ 122, Vol. 41, enero, Santiago.

Calderón, J. (2011.) Titulación de la propiedad y mercado de tierras. En EURE $\mathrm{N}^{\circ} 111$, Vol. 37, mayo, Santiago.

Calderón, J. (2009). El efecto Mivivienda: política de vivienda para la clase media y diferenciación social. En Ecuador Debate N. ${ }^{\circ} 76$. Quito: Caap.

Calderón, J. (2006). Mercado de tierras urbanas, propiedad y pobreza. Lima: SINCOS- LILP.

De Soto, H. (1990). El otro Sendero. Lima: Instituto Libertad y Democracia.

De Soto, H. (2000). El misterio del capital. Lima: El Comercio.

Ccanre Salazar, P. (2016). La tierra prometida. Las invasiones en la zona agropecuaria de Villa El Salvador y la Nueva Rinconada en San Juan de Miraflores, Lima 2000. Tesis para optar el grado de Licenciado en Historia en la Universidad Nacional Mayor de San Marcos, Lima.

ESAN-IMASEN (2004). Segunda encuesta de hogares para la medición del impacto del Proyecto Derechos de Propiedad Urbana en el bienestar de la población. Informe final. Lima: COFOPRI.

García Montúfar, G. (2002). Los sistemas de administración de tierras en el Perú. Lima: Banco Mundial.

Iracheta, A. (2015). Ciudad informal y precaria: la otra cara de la urbanización mexicana. En G. Olivera (coordinador) La urbanización social y privada del ejido: ensayos sobre la dualidad del desarrollo urbano en México. México: UNAM.

Morris, F. (2004). Develando el misterio. La formalización de la propiedad en el Perú. Lima: COFOPRI-Banco Mundial.

MVCS, Ministerio de Vivienda, Construcción y Saneamiento (2018). Borrador del Plan Nacional de Vivienda 2018-2030. Lima: MVCS.

MVCS, Ministerio de Vivienda, Construcción y Saneamiento (2014). Situación de los barrios urbano marginales en el Perú 2012, Segunda aproximación. Lima: MVCS.

MVCS, Ministerio de Vivienda, Construcción y Saneamiento (2006). Plan Nacional de Vivienda 2006-2015. Lima: MVCS.

MVCS, Ministerio de Vivienda, Construcción y Saneamiento (2005). Situación de los barrios urbano marginales en el Perú 2004, Primera aproximación. Lima: MVCS.

Perú, República de (2011). Obras para el pueblo. Así avanzó el Perú. Cinco años invirtiendo en los más pobres 2006-2011. Lima: Ministerio de la Presidencia.

Pimentel, N. (2015). Subalternos autónomos. Transformaciones periurbanas y tráfico de tierras en contextos de sociedad de mercado: Carabayllo. Borrador de tesis. Lima: UNMSM.

Portes, A. (1995). En torno a la informalidad: ensayos sobre teoría y medición de la economía no regulada. México: Prorrúa-Facultad Latinoamericana de Ciencias Sociales.

Poulantzas, N. (1979). Estado, poder y socialismo. México: Siglo XXI. 
Julio Calderón Cockburn

Reyes, M. (2010). La politica de la propiedad informal y el desarrollo de Barrios Urbano Marginales en zonas de riesgo en Lima Metropolitana a partir de la década del 90. Casos: Comas e Independencia. Borrador de tesis de maestría, UNI.

SAssen, S. (2003). Los espectros de la globalización. Buenos Aires: FCE. 